\title{
Glyphidops (Glyphidops) filosus (Diptera: Neriidae) revisited, with special attention to the morphology of the male and female terminalia
}

\author{
Isabela de Oliveira Motta ${ }^{1,2}$ \& José Roberto Pujol-Luz ${ }^{1,3}$ \\ 1 Universidade de Brasília (UNB), Instituto de Ciências Biológicas (IB), Departamento de Zoologia. Brasília, DF, Brasil. \\ 2 ORCID: http://orcid.org/0000-0002-8777-2817. E-mail: isabela.motta94@gmail.com \\ 3 ORCID: http://orcid.org/0000-0002-8621-4856. E-mail: jrpujol@unb.br
}

\begin{abstract}
Although a recent revision of the genus Glyphidops Enderlein covered most its known, some of the Brazilian forms were not surveyed. Here we take advantage of the excellent morphological work available in the literature and redescribe Glyphidops (Glyphidops) filosus, based on 91 specimens (43 males and 48 females) from the States of Amazonas and Goiás, including Brasília, Brazil. We also provide a study of male genitalia using scanning electron microscopy (SEM) and female genitalia and spermathecae, using light microscopy (LM). We present descriptions of the following structures in male genitalia: epandrium, hypandrium, surstyli, cerci and sections of aedeagus, and in female genitalia: oviscape, bursa copulatrix, ' $S$ ' bend and spermatheca. An update list of Brazilian species of Glyphidops Enderlein is also presented.
\end{abstract}

Key-Words. Cactus flies; Cerrado vegetation; Genitalia; Scanning electron microscopy; Taxonomy.

\section{INTRODUCTION}

In a recent study of the genus Glyphidops Enderlein, Sepúlveda et al. (2014) presented a comprehensive taxonomic study including the redescription of the type species, a new diagnosis of the genus and for most of the species, and described three new species. They also provide an identification key to the species and mapped their geographic distribution. The authors recognized 14 species for this genus: Glyphidops (Glyphidops) bullatus (Enderlein); G. (G.) coracinus, Sepúlveda, Wolff \& De Carvalho; G. (G.) etele Aczél; G. (G.) filosus (Fabricius); G. (G.) obscurus Hennig; G. (G.) ruselatus, Sepúlveda, Wolff \& De Carvalho; G. (G.) steyskali, Sepúlveda, Wolff \& De Carvalho; G. (G.) vittatus (Cresson); G. (G.) xanthopus (Schiner); Glyphidops (Oncopsia) carrerai Aczél; G. (O.) durus (Cresson); G. (O.) flavifrons (Bigot); G. (O.) limbatus Enderlein and $G$. (O.) pluricellatus (Schiner).

Although Sepúlveda et al. (2014) redescribed Glyphidops (G.) filosus based on the examination of photographs of the type material from the Zoologisk Museum Statens Naturhistoriske Museum (UZMC), different to other material they studied, for this species they did not present any information on the morphology of the male and female terminalia. Aczél (1961) was the last author to present a brief morphological description of these morphological aspects of this species.
Here we redescribe Glyphidops (G.) filosus with attention to the external and internal male and female genitalia. In male genitalia we show the presence of epandrium, hypandrium, surstyli, cerci, basal section of aedeagus, middle section of aedeagus, distal section of aedeagus, complex hinge of aedeagus, lateral arms, pregenital muscles, aedeagal apodeme. In the female genitalia we show the presence of a bursa copulatrix, ' $S$ ' bend, a dorsal oviscape, modified cerci, four spermathecal capsules and spermathecal ducts. An update list of Brazilian species of Glyphidops Enderlein is also presented.

\section{MATERIAL AND METHODS}

We examined 91 specimens (43 males and 48 females) of Glyphidops (G.) filosus, 71 were collected in Distrito Federal, Brazil, of which 49 were caught in Fazenda Água Limpa (15 56 $45^{\prime \prime}$, $\left.47^{\circ} 56^{\prime} 80^{\prime \prime} \mathrm{W}\right)$ and 22 in Estação Experimental de Biologia $\left(15^{\circ} 44^{\prime} 39,0^{\prime \prime} \mathrm{S}, 47^{\circ} 52^{\prime} 38,7^{\prime \prime} \mathrm{W}\right)$ of Universidade de Brasília. These specimens were collected with Van Someren-Rydon (Fig. 1A-1B) and PET bottle traps coated with yellow paint. We also studied 15 specimens collected in the Varjão county $\left(17^{\circ} 02^{\prime} 43^{\prime \prime} \mathrm{S}, 49^{\circ} 37^{\prime} 52^{\prime \prime} \mathrm{W}\right)$, state of Goiás, with Malaise traps. The remaining five specimens, which had been originally collected in Amazonas 
and Goiás states, were acquired from the collection of Museu de Zoologia, Universidade de São Paulo.

Material examined: 43 males, 48 females. Males: Brazil, Distrito Federal, Brasília, Estação Experimental de Biologia, 1544'39,0"S, 4752'38,7"W, 11/04/2018, Motta, I. Col., UNB016769;07/05/2018, Motta, I. Col., UNB016709; 13/11/2018, Motta, I. Col., UNB019031, UNB019292; 12/03/2019, Motta, I. Col., UNB018654, UNB018865, UNB019195; 04/04/2019, Motta, I. Col., UNB018659, UNB018779, UNB019085, UNB019221; Fazenda Água

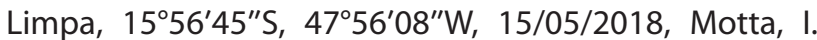
Col., UNB016679, UNB016814, UNB017529; 22/05/2018, Motta, I. Col., UNB016963, UNB017069, UNB017243, UNB017293, UNB017531; 11/07/2018, Motta, I. Col., UNB017088, UNB018639; 19/09/2018, Motta, I. Col., UNB016839, UNB017045, UNB017145; 04/10/2018, Motta, I. Col., UNB018681, UNB018841; 11/10/2018, Motta, I. Col., UNB018590, UNB018776; 18/10/2018, Motta, I. Col., UNB018734, UNB018778, UNB018925; 25/10/2018, Motta, I. Col., UNB019185, UNB019295; Goiás, Varjão $17^{\circ} 02^{\prime} 43^{\prime \prime} \mathrm{S}, 4^{\circ} 37^{\prime} 52^{\prime \prime} \mathrm{W}, 02 / 01 / 2019$, Lopes, W.R. Col., UNB018644, UNB018768, UNB019062, UNB019227; 03/02/2019, Lopes, W.R. Col., UNB018615, UNB018762, UNB018986, UNB019124; Goianésia, 15¹9'33"S, 49²'2"W, 06/IX/1969, H. Ebert Col., MZUSP; Amazonas, Puruzinho, 14-17/XI/3-6/XII/1975, Exp. Perm. Amaz., MZUSP. Females: Brazil, Distrito Federal, Brasília, Estação Experimental de Biologia, 1544'39,0"S, 47 52'38,7"W, 11/04/2018, Motta, I. Col., UNB017456; 13/11/2018, Motta, I. Col., UNB018927, UNB019077; 12/03/2019, Motta, I. Col., UNB018606, UNB018695, UNB018791, UNB019315, UNB019356; 04/04/2019, Motta, I. Col., UNB016865, UNB018617, UNB019335;

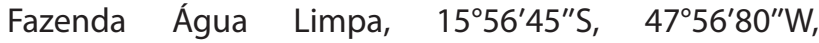
22/05/2018, Motta, I. Col., UNB016753, UNB017440, UNB017501，UNB017518， UNB017544; 05/06/2018, Motta, I. Col., UNB016579, UNB016852; 11/07/2018, Motta, I. Col., UNB016888, UNB017058, UNB018530; 01/08/2018, Motta, I. Col., UNB016978; 30/08/2018, Motta, I. Col., UNB017462; 19/09/2018, Motta, I. Col., UNB016685, UNB017347, UNB017403; 04/10/2018, Motta, I. Col., UNB018759, UNB018984, UNB019016; 11/10/2018, Motta, I. Col., UNB018761, UNB018831, UNB019190; 18/10/2018, Motta, I. Col., UNB018580, UNB018903; 25/10/2018, Motta, I. Col., UNB018832, UNB018964, UNB019240; 04/12/2018, Motta, I. Col., UNB190160; Goiás, Varjão 1702'43"S, 49³7'52"W, 02/01/2019, Lopes, W.R. Col., UNB018867, UNB019179, UNB019242; 03/02/2019, Lopes, W.R. Col., UNB018568, UNB018572, UNB018646, UNB019078; Goianésia, $15^{\circ} 19^{\prime} 33^{\prime \prime} \mathrm{S}, 49^{\circ} 7^{\prime} 2^{\prime \prime} \mathrm{W}, 06 / \mathrm{IX} / 1969$, H. Ebert Col., MZUSP.

Dissected material: Male: UNB016679, UNB016709, UNB016814, UNB016963, UNB017069, UNB017293, UNB017529, UNB017531. Female: UNB016579, UNB016753, UNB016852, UNB016888, UNB016978, UNB017058, UNB017347, UNB017440, UNB017456, UNB017462, UNB017501, UNB017518, UNB017544, UNB018530, UNB018750, UNB019240.
The male genitalia were processed through diaphanization of the abdomen with $10 \% \mathrm{KOH}$ heated, for about 12 minutes and the female genitalia were processed through diaphanization of the abdomen with Lactic acid heated, for about eight minutes. Subsequently, they were washed in water and stored in alcohol for dissection. Photographs were taken with light microscopy (LM) using Leica DFC295 camera mounted on Leica M205 C stereomicroscope and Leica DM2000 microscope. The specimens were measured $(\mathrm{mm})$ with the software Leica LAS-V3.8. For analysis with Scanning Electron Microscopy (SEM), the samples were dehydrated in acetone at concentrations of $30 \%, 50 \%, 70 \%, 90 \%$ and $100 \%$; taken to the critical point drying process with $\mathrm{CO} 2$, assembled in stubs, metallized with gold and visualized in a scanning electron microscope JEOL JSM 7001F. The terminology for the external morphology follows Aczél (1959), Steyskal (1987), Buck (2010), Bath et al. (2012), Sepúlveda et al. (2014) and Cumming \& Wood (2017).

\section{RESULTS}

This redescription increases the Sepúlveda et al. (2014) work in the following characters: (1) Head-morphological characteristics of the frontal vitta; number of setae on fronto-orbital plate; brownish stripes measurements on the side of the head; genal seta strong; measurements of antennal base, scape and pedicel; coloration and measurements of first flagellomere and arista. (2) Thorax-coloration of longitudinal stripes of pronotum and mesonotum; longitudinal stripe of male and female scutellum; proepisternum coloring; number of katerpisternum setae. (3) Legsfore coxa color and number of setae in males and females; fore femur spines number and mid coxa coloration; male and female mid femur, hind coxa and hind femur spine number; tibial spurs. (4) Wing-seta on basicosta; morphological characteristics of Sc, R1, R4 + 5, M1 and dm-cu veins; morphological characteristics of br cell; fringe of calyptra; wing dorsal portion coloration. (5) Abdomentergites coloration and setulae; oviscape setulae.

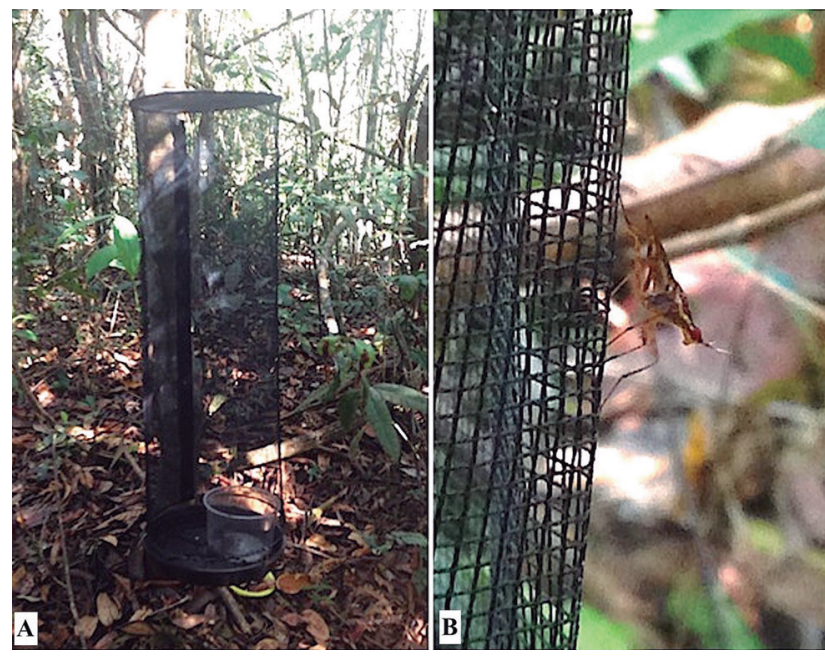

Figure 1. (A) Van Someren-Rydon trap; (B) Specimen of Glyphidops (Glyphidops) filosus. 

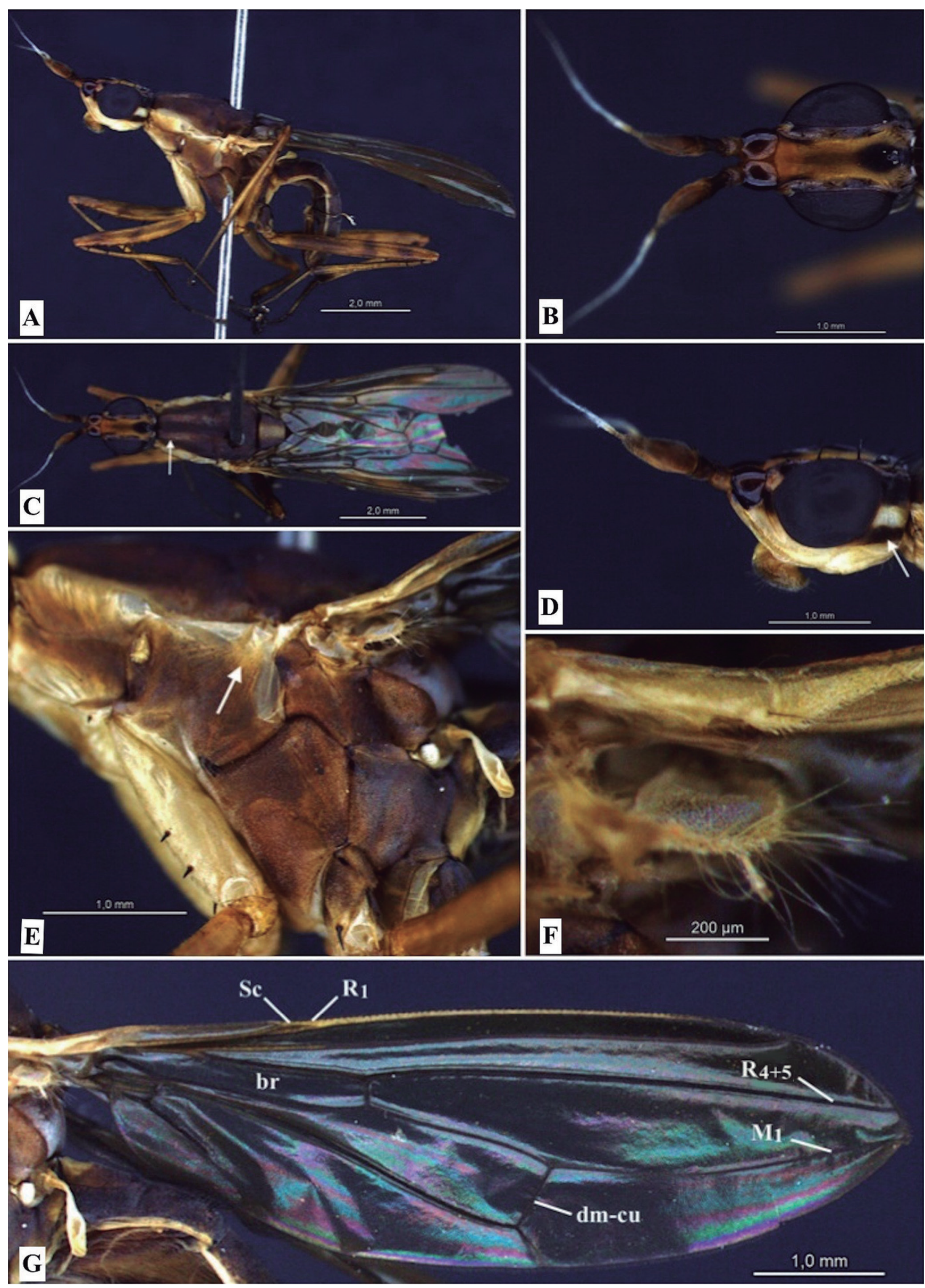

Figure 2. Glyphidops (Glyphidops) filosus (Fabricius). (A) Male, habitus; (B) Head, dorsal view; (C) Body, dorsal view. Arrow indicates stripes of the thorax; (D) Head, lateral view. Arrow indicates brownish stripe; (E) Arrow indicates anepisternum dorsally lighter than the pleura; (F) Calypter with fringe of yellowish bristles; (G) Wing. 


\section{Glyphidops (Glyphidops) filosus (Fabricius, 1805)}

Male: Body length 8,0-9,6 mm (Fig. 2A). Head elongated sideways, length varying between 1,5-1,7 mm (Fig. 2B). Ocellar triangle slightly prominent, surrounded by black oval spot at the frontal vitta posterior portion. Frontal vitta yellowish, narrow and long with longitudinal central concavity. Fronto-orbital plate brownish and with 3-4 setae, when present, the fourth seta is significantly lower than the others. Outer vertical seta divergent, inner vertical seta convergent and postocellar seta strongly convergent. Head in lateral view with one brownish stripe at the posterior portion, length $0,4-0,6 \mathrm{~mm}$ and width $0,1-0,2 \mathrm{~mm}$ (Fig. 2D). Strong genal seta. Postgena with setulae. Antennal base shiny brown with length 0,3-0,4 mm and width 0,2-0,3 $\mathrm{mm}$. Scape brown with yellowish base, length 0,2-0,3 mm and width 0,1-0,2 mm, with setulae at the anterior portion. Pedicel dark brownish with inner process yellowish, length 0,4-0,6 $\mathrm{mm}$ and setulae all around the structure. First flagellomere lanceolate, yellowish at the posterior portion and brownish at the middle-anterior region, length 0,4-0,6 mm, covered with setulae. Arista yellowish at the posterior region, with white pubescence along the structure, length 1,1-1,5 mm.

Thorax: Pronotum and mesonotum with two lighter brownish longitudinal stripes separated by one darker medial stripe, which has the same color of the thorax
(Fig. 2C). Anterior notopleural seta absent and posterior seta present. Supra-alar seta absent and postalar seta present. Scutellum wider at the anterior portion and thinner distally, with one wide yellow longitudinal stripe. Proepisternum with lighter color than the pleura, with short anteroventral seta. Anepisternum dorsally lighter than the pleura (Fig. 2E). Katerpisternum with 1-2 setae.

Legs: Fore coxa yellowish with three setae, in frontal view two lateral and one distal near the trochanter. Fore femur with 8-14 spines at the ventral portion. Mid coxa with brownish color and two lateral setae. Mid femur with 2-3 lateral spines at the anterior portion and six distal spines at the ventral portion. Hind coxa with two lateral setae, femur with 5-6 spines at ventral portion. Femora with yellowish-brown coloration and subtle brownish stripes. Tibia with a pair of distal spurs.

Wing: Length 6,1-7,0 mm. Basicosta with small seta at the apex. Sc and $R_{1}$ veins very close to each other, with slight bifurcation near the costal vein. $R_{4+5}$ and $M_{1}$ are convergent. The br cell is open in the wing basal portion and $\mathrm{dm}$-cu vein is lightly concave. Fringe of yellowish setae on the calyptra edge (Fig. 2F). Dorsal portion with slightly darkened coloration (Fig. 2G). Halter whitish-yellow.

Abdomen: Tergites usually with dark brownish coloration, yellowish just in some specimens. Sternites yel-
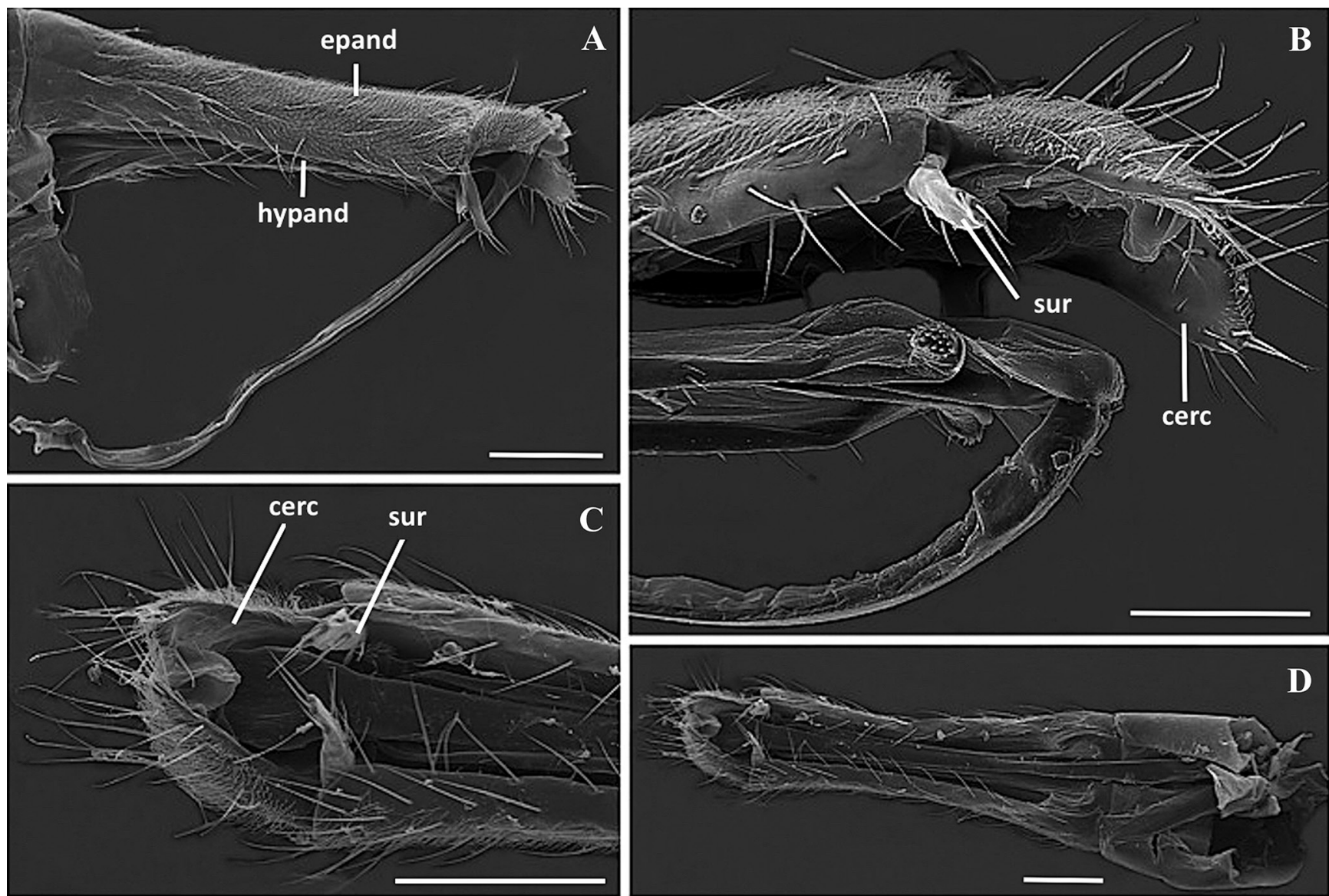

Figure 3. Male terminalia. (A) Epandrium and hypandrium, lateral view; (B) Cerci and surstyli, lateral view; (C) Cerci and surstyli, ventral view; (D) Male terminalia, ventral view. epand $=$ epandrium, hypand $=$ hypandrium, cerc $=$ cerci, sur $=$ surstyli. Scales: $(A-D) 100 \mu m$. 
lowish. Tergite I-V covered with a thin layer of small black setulae, tergite $\mathrm{VI}$ and epandrium with longer apical setae. Epandrium shiny with brownish coloration and paler than the rest of the abdomen.

Female: Similar to male, except: length 7,4-9,1 mm. Postocellar seta convergent or parallel in some specimens. Scutellum with thin yellow longitudinal stripe and with stronger coloration. Katepisternum without seta. Fore coxa with one distal seta near the trochanter. Mid femur with three lateral setae at the anterior portion and 6-7 distal spines at the ventral portion. Hind femur with 8-9 spines at the ventral portion. Ventral portion of the abdomen with coloration like the dorsal portion. Tergites
I-V with few setae. Oviscape dorsally darkish-brown and ventrally yellowish, with short and sparse setulae along the structure (Fig. 5A).

\section{Male and female terminalia}

Aczél (1961) described briefly the male and female terminalia of the species Glyphidops (Glyphidops) filosus. In the description of male terminalia, the mentioned structures were cerci, syntergite $7+8$ and epandrium, with the respective measures of length. The structures of female terminalia were the characteristics of oviscape, like coloration and measures of length. In Sepúlveda et al. (2014) the structures of male terminalia mentioned
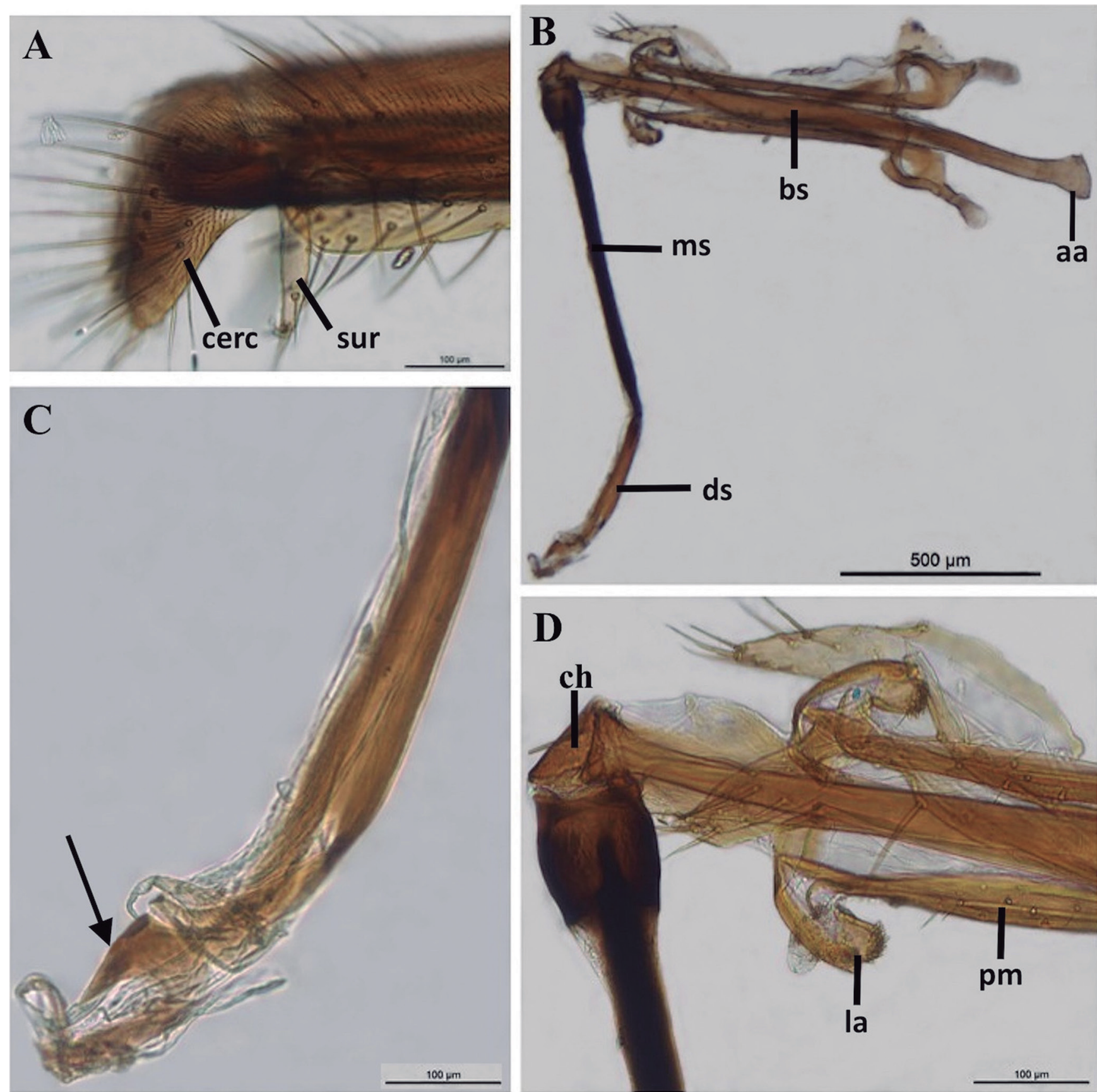

Figure 4. Male terminalia. (A) Surstyli and cerci, lateral view; (B) Aedeagus; (C) Arrow indicates aedeagus with division in the apical region; (D) Basal section connected to middle section by a complex hinge. sur = surstyli, cerc $=$ cerci, bs = basal section, $\mathrm{ms}=$ middle section, $\mathrm{ds}=$ distal section, aa = aedeagal apodeme, $\mathrm{ch}=$ complex hinge, la = lateral arms, $\mathrm{pm}=$ pregenital muscles 

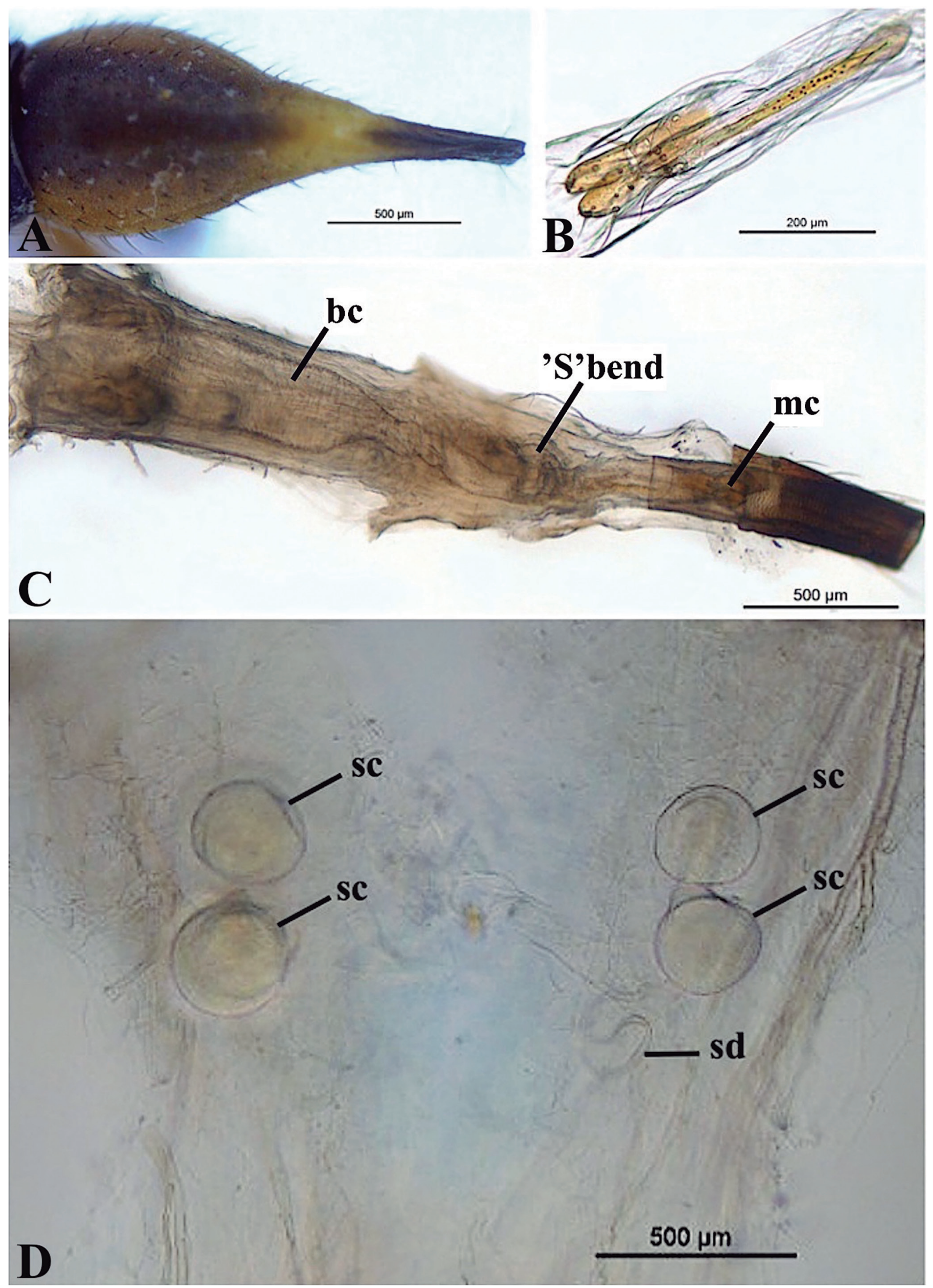

Figure 5. Female terminalia. (A) Oviscape dorsal view; (B) Modified cerci dorsal view; (C) female genitalia dorsal view; (d) Spermathecal capsules. bc = bursa copulatrix, $\mathrm{mc}=$ modified cerci, $\mathrm{sc}=$ spermathecal capsules, $\mathrm{sd}=$ spermathecal duct. 
were syntergite $7+8$ and coloration of the epandrium, and for females the oviscape coloration and measurements of the length.

Male Terminalia: Length 0,9-1,2 $\mathrm{mm}$. Epandrium and hypandrium yellowish and long, with short setae (Fig. 3A). Cerci and surstyli with sparse setae (Fig. 3B); cerci with apical process turned ventrally (Fig. 3C-D, Fig. 4A). Aedeagus long with three sections, basal, middle and distal (Fig. 4B); bifid, with division appearing in the apical region of the distal section (Fig. $4 \mathrm{C}$ ). The basal and middle sections have a complex hinge between them (Fig. 4D). Basal section with lateral arms with short apical spines and long pregenital muscles (Figs. 3B, 4D). Middle section with one spine at the anterior portion. Distal section with spines at the apical portion. Aedeagal apodeme at the posterior portion of the basal section of aedeagus.

Female terminalia: Length 1,4-2,3 mm. Ovipositor with modified cerci in its distal portion. Modified cerci have an approximate length of 0,5 $\mathrm{mm}$, yellowish, bifurcated and with setae at the apex in the posterior portion (Fig. 5B). Ovipositor leads to the tube that passes through the ' $S$ ' bend and connects with the bursa copulatrix. Bursa copulatrix connects to ducts of the spermatheca, followed by the four spermathecal capsules (Fig. 5C). Spermathecal capsules are spherical structures (Fig. 5D).

\section{COMMENTS}

Koch et al. (2015) presented the first phylogenetic study of Neriidae. The characters surveyed were all from external morphology. The monophyletic subfamily Neriinae includes the two genera whose genital morphology is now known: Glyphidops Enderlein (present work) and Telostylinus Enderlein (Bath et al., 2012). These two taxa are in separate clades, Telostylinus Enderlein is in Eoneria-group and Glyphidops Enderlein is in Neriusgroup. From the illustrations and descriptions presented in Bath et al. (2012) it is possible infer that males of Telostylinus lineolatus (Wiedemann) possess a spine in the middle section of aedeagus, differing from the male of Glyphidops (G.) filosus, that does not show this character; and females differ in the number of spermathecal capsules, three in Telostylinus angusticollis (Enderlein), two in T. lineolatus and four in Glyphidops (G.) filosus. It would be premature and speculative to advance any discussion on the meaning of these differences at this point and further studies with larger set of taxa are still necessary for us to understand the meaning of this variation in any aspect.

\section{List of the species of Glyphidops from Brazil}

\section{Glyphidops (Glyphidops)}

etele Aczél, 1961: 302. Distribution: Brazil (São Paulo, Juquiá. Distribution: Amazonas, Minas Gerais, São Paulo); Ecuador; Peru. filosus (Fabricius), 1805: 265. Distribution: Guatemala; Montserrat; Honduras; Nicaragua; Trinidad; Costa Rica; Panama; Colombia; Venezuela; Guyana; Suriname; Brazil (Acre, Alagoas, Amazonas, Bahia, Goiás, Distrito Federal (new record), Espírito Santo, Mato Grosso do Sul, Pará, Paraíba, Rio de Janeiro, Roraima, São Paulo); Ecuador; Peru.

vittatus (Cresson), 1912: 390. Distribution: Guyana; Brazil (Amazonas); Peru; Bolivia.

\section{Glyphidops (Oncopsia)}

carrerai Aczél, 1961: 316. Distribution: Guyana; Colombia; Brazil (Amazonas, Bahia, Pará, Paraíba, Rio de Janeiro, São Paulo).

durus (Cresson), 1926: 260. Distribution: Costa Rica; Panama; Colombia; Venezuela; Brazil (Amazonas, Amapá, Pará, Paraná, São Paulo); Ecuador; Peru; Bolivia; Argentina.

flavifrons (Bigot), 1886: 372. Distribution: Mexico; Honduras; Nicaragua; Trinidad and Tobago; Costa Rica; Panama; Colombia; Guyana; Brazil (Amazonas, Acre, Distrito Federal (new record), Espírito Santo, Pará); Ecuador; Bolivia.

limbatus Enderlein, 1922: 151. Distribution: Brazil (Acre, Amapá, Amazonas, Minas Gerais, Pará, Rio de Janeiro, Rondônia, Roraima, São Paulo, Santa Catarina).

\section{ACKNOWLEDGMENTS}

We are thankful to Dr. Carlos José Einicker Lamas from the Museu de Zoologia da Universidade de São Paulo for the loan of some specimens used in this study. To Dr. Welinton Ribamar Lopes for helping with the collections made in Goiás. To Conselho Nacional de Desenvolvimento Científico e Tecnológico/CNPq and Fundação de Apoio à Pesquisa do Distrito Federal/FAPDF (JRPL), Programa de Pós-Graduação em Zoologia and Universidade de Brasília and Coordenação de Aperfeiçoamento de Pessoal de Nível Superior/CAPES (IOM) for the grants. To Gabriela de Oliveira Motta, Alexandre Ariel da Fonseca de Souza and Hélio Ricardo da Silva for reviewing different parts of the manuscript. To the colleagues of Laboratório de Diversidade de Insetos do Cerrado who helped with the field collections.

\section{REFERENCES}

Aczél, M.L. 1959. Diptera: Neriidae and Micropezidae (Tylidae). Insects of Micronesia, 14(3): 51-65.

Aczél, M.L. 1961. A revision of American Neriidae (Diptera, Acalyptratae). Studia Entomologica, Rio de Janeiro, 4: 257-346.

Bath, E.; Tatarnic, N. \& Bonduriansky, R. 2012. Asymmetric reproductive isolation and interference in neriid flies: the roles of genital morphology and behaviour. Animal Behaviour, 84(6): 1331-1339. 
Bigot, J.M.F. 1886. Essai Dúne classification synoptique du groupe Tanypezidi. Annales de la Société Entomologique de France, 6: 372-373.

Buck, M. 2010. Neriidae. In: Brown, B.V., Borkent, A., Cumming, J.M., Wood, D.M., Woodley, N.E. \& Zumbado, M. (Eds.). Manual of Central American Diptera. Ottawa, NRC Research Press. v. 2, p. 815-819.

Cresson, E.T. 1912. Descriptions of several new neotropical acalyptrate Diptera. Descripciones de numerosos nuevos Diptera acalyptrate. Entomological News, 23: 389-396.

Cresson, E.T. 1926. Descriptions of new genera and species of Diptera (Ephydridae and Micropezidae). Transactions of the American Entomological Society, 52: 249-274.

Cumming, J.M. \& Wood, D.M. 2017. Adult morphology and terminology in manual of Afrotropical Diptera. In: Kirk-Spriggs, A.H. \& Sinclair, B.J. (Eds.). Manual of Afrotropical Diptera. Pretoria, South Africa, SANBI Publishing. v. 1, p. 89-133.
Enderlein, G. 1922. Klassifikation der Micropeziden. ArchivfürNaturgeschichte, 88: $140-229$.

Fabricius, J.C. 1805. Glyphidops (Glyphidops) filosus. In: Systema antliatorum secundum ordines, genera, species, adiectis synonyms, locis, observationibus, descriptionibus. Brunsvigae, Reichard. p. 264-265.

Koch, N.M.; Soto, I.M. \& Ramírez, M.J. 2015. First phylogenetic analysis of the family Neriidae (Diptera), with a study on the issue of scaling continuous characters. Cladistics, 31: 142-165.

Sepúlveda, T.A.; Wolff, M.I. \& De Carvalho, C.J. 2014. Revision of the New World genus Glyphidops Enderlein (Diptera: Neriidae). Zootaxa, 3785(2): 139-174.

Steyskal, G.C. 1987. Neriidae. In: McAlpine J.F., Peterson B.V., Shewell G.E., Teskey H.J., Vockeroth J.R. \& D.M. Wood. (Eds.). Manual of Nearctic Diptera. Ottawa, Canadian Government Publishing Center. Volume 2, p. 769-771. 